Military Technical College

Kobry El-Kobbah, Cairo, Egypt

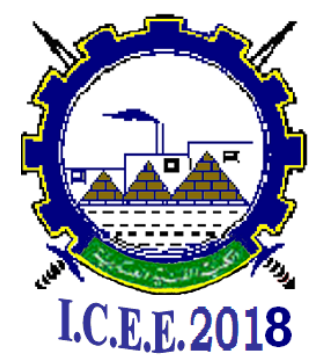

$9^{\text {th }}$ International Conference on

Chemical \& Environmental

Engineering

3-5 April 2018

\title{
SMD-5
}

\section{Influences of operating conditions of surface dielectric barrier discharge on the decomposition of gaseous naphthalene}

\author{
Ayman A. Abdelazizı, Tatsuo Ishijima2, Takafumi Seto3
}

\begin{abstract}
Polycyclic aromatic hydrocarbons (PAHs) have received a considerable research interest due to their toxic and carcinogenic effects [1]. Therefore, it is important to remove these compounds before their emission into the ambient air.

Nowadays, nonthermal plasma is considered as an emerging technology to remove volatile organic compound (VOC) emissions and other industrial exhausts. The main feature of nonthermal plasma is the generation of reactive species such as $\mathrm{O}, \mathrm{O}_{3}$, and $\mathrm{OH}$, which are capable of decomposing organic pollutants at the atmospheric pressure and temperature.

In a previous work [2], we developed a new plasma reactor based on surface dielectric barrier discharge (SDBD). The performance of this reactor has been tested for the decomposition of naphthalene at different initial concentrations of naphthalene and different flow rate.

Herein, we systematically explore the influences of the operating conditions, in terms of the oxygen content, the relative humidity, the applied voltage and the frequency on the decomposition of naphthalene. Naphthalene, a two-ring compound, was chosen as a model pollutant because it is the most abundant PAH in urban air, where its concentration is often greater than those of all other PAHs combined [3].

The main results of this study showed that the decomposition efficiency decreases with the increase of the oxygen content reaching a minimum value at a small content of oxygen and relatively high input power, and then increases at higher oxygen content. In addition, it is found that there is an optimum level of the humidity for the decomposition of the naphthalene in the SDBD, and this value depends on the gas composition. Furthermore, the decomposition efficiency is increased with increasing the applied voltage and frequency due to the increase in the power; which leads to an increase in the reactive species in the reactor with a subsequent increase the decomposition efficiency. The effects of the operating conditions on the characteristics of the SDBD, including the current-voltage waveform, and the power consumed is presented in this work.
\end{abstract}

\section{References}

1. Keith L and Telliard W 1979 Priority pollutants: I. A perspective view, ES\&T Special Report Environ. Sci. Technol. 13 416-23

2. Bunce N, Liu L and Zhu J 1997 Reaction of naphthalene and Its derivatives with hydroxyl radicals in the gas phase Environ. Sci. Technol. 31 2252-9 
Military Technical College

Kobry El-Kobbah, Cairo, Egypt

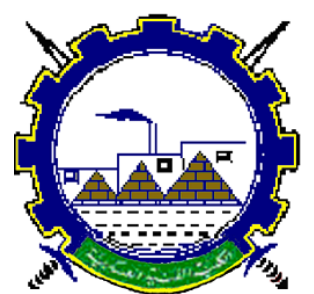

I.C.E.E.2018 $9^{\text {th }}$ International Conference

on

Chemical \& Environmental

Engineering

3-5 April 2018

3. Abdelaziz A, Seto T, Abdel-Salam M and Otani Y 2012 Performance of a surface dielectric barrier discharge based reactor for destruction of naphthalene in an air stream $\mathrm{J}$. Phys. D: Appl. Phys. 45115201

1. Physics Department, Faculty of Science, Assiut University, Assiut, Egypt

2. Research Center for Sustainable Energy and Technology, Kanazawa University, Kanazawa, Japan.

3. School of Natural System, Kanazawa University, Kanazawa, Japan

Corresponding author Email: a.abdelaziz@ science.au.edu.eg, Tel: +201065380078 